\title{
What is the use of directional atherectomy, now \\ we have stents?
}

Director, Cardiac Catheterization Laboratory, Columbus Hospital Milan, via $M$ Buonarroti 48, 20145 Milan, Italy

\author{
Antonio Colombo
}

Table 1 Historical evolution of DCA

\begin{tabular}{cllc}
\hline Year & Product & Indications for atherectomy & $\begin{array}{l}\text { DCAs } \\
\text { worldwide }\end{array}$ \\
\hline 1990 & SCA-1 & Proximal LAD, RCA, grafts & 2175 \\
1991 & LP & $\begin{array}{l}\text { Proximal LAD, RCA, grafts, high risk PTCA, } \\
\text { failed PTCA }\end{array}$ & 15000 \\
1992 & EX & Above, ostial, bifurcations & 32000 \\
1993 & Short cutter & Above, distal & 44000 \\
1994 & GTO, 7F Graft & Above, larger vessels & 44108 \\
1995 & None & Complex lesion morphologies & 28000 \\
1996 & None & Complex lesion morphologies & 12038 \\
1997 & Bantam & Debulk prior to stenting & \\
\hline
\end{tabular}

$\mathrm{LAD}$, left anterior descending coronary artery; RCA, right coronary artery; PTCA, percutaneous transluminal coronary angioplasty.

Table 2 Timing of major clinical trials with DCA and competing events

\begin{tabular}{|c|c|c|c|c|}
\hline Year & Trial started & Completed & Published & Competing events \\
\hline $\begin{array}{l}1990 \\
1991\end{array}$ & $\begin{array}{l}\text { CAVEAT } 1 \text { natives } \\
\text { CCAT, Prox LAD }\end{array}$ & & & DCA FDA approved \\
\hline $\begin{array}{l}1992 \\
1993\end{array}$ & CAVEAT 2 grafts & $\begin{array}{l}\text { CAVEAT } 1 \\
\text { CCAT }\end{array}$ & $\begin{array}{l}\text { CAVEAT } 1 \\
\text { CCAT }\end{array}$ & $\begin{array}{l}\text { Rotablator FDA approved } \\
\text { Stents FDA approved }\end{array}$ \\
\hline $\begin{array}{l}1994 \\
1995\end{array}$ & $\begin{array}{l}\text { OARS } \\
\text { BOAT, ABACAS }\end{array}$ & OARS & $\begin{array}{l}\text { CAVEAT } 1 \\
1 \text { year data }\end{array}$ & $\begin{array}{l}\text { Optimal DCA } \\
\text { Ticlodipine }+ \text { aspirin }+ \\
\text { optimal stent implantation }\end{array}$ \\
\hline $\begin{array}{l}1996 \\
1997\end{array}$ & SOLD & $\begin{array}{l}\text { BOAT } \\
\text { ABACAS } \\
\text { SOLD }\end{array}$ & & \\
\hline
\end{tabular}

Table 3 Summary of major DCA trials

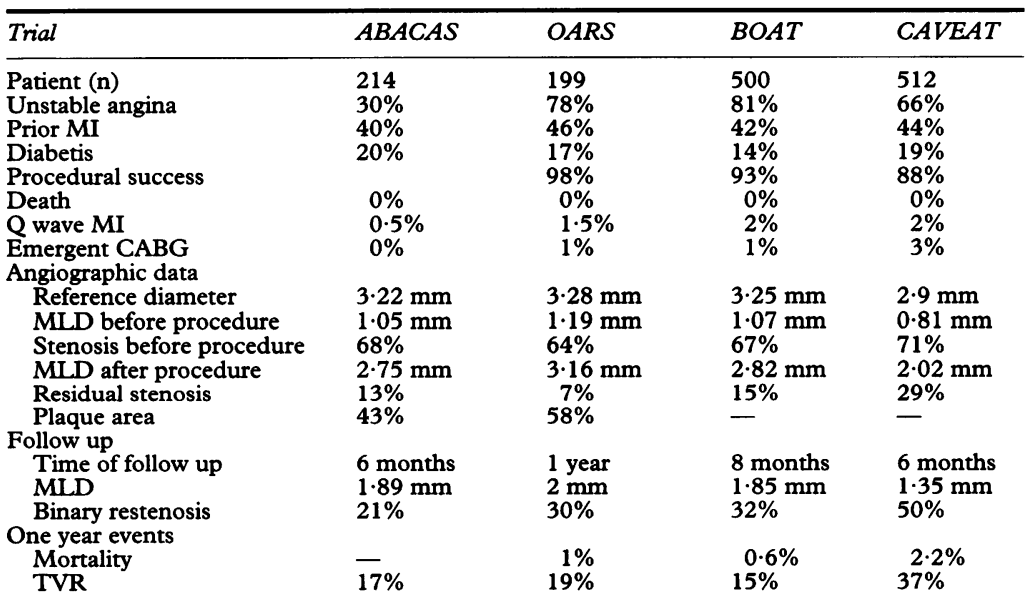

MI, myocardinal infarction; CABG, coronary artery bypass graft; MLD, minimal lumen diameter; TVR, target vessel revascularisation.

Table 4 Preliminary data of a registry with DCA and stenting of 92 patients (Stenting after Optimal Lesion Debulking: SOLD Registry)

\begin{tabular}{llclc}
\hline & Baseline & Post-DCA & Post-stent & Follow up \\
\hline Reference diameter & $3.27 \mathrm{~mm}$ & $3.32 \mathrm{~mm}$ & $3.52 \mathrm{~mm}$ & $3.21 \mathrm{~mm}$ \\
MLD & $0.84 \mathrm{~mm}$ & $2.29 \mathrm{~mm}$ & $3.48 \mathrm{~mm}$ & $2.69 \mathrm{~mm}$ \\
Stenosis & $74 \%$ & $31 \%$ & $0.7 \%$ & $17 \%$ \\
Lesion length & $12.30 \mathrm{~mm}$ & $49 \%$ & & $4.70 \mathrm{~mm}$ \\
Plaque area & $78 \%$ & & & $4.9 \%$ \\
Binary restenosis & & & & $3.8 \%$ \\
TVR & & &
\end{tabular}

MLD, minimal lumen diameter; TVR, target vessel revascularisation.
In the past few years directional coronary atherectomy (DCA) has been hit by unfavourable reports such as the results of the Coronary Angioplasty Versus Excisional Atherectomy Trial (CAVEAT) ${ }^{1}$ and the Canadian Coronary Atherectomy Trial (CCAT). ${ }^{2}$ The history of DCA is summarised in table 1 , which shows a sustained increase in the number of procedures until 1993-94 and then a rapid downfall. The timing of the major trials of DCA and competing events are shown in table 2. Besides the negative results of the CAVEAT and the CCAT trials, the introduction of coronary stents has been the major element to contribute to the downfall of DCA. The increase in use of stents, made more palatable by the elimination of anticoagulant treatment, ${ }^{3-5}$ shadowed the positive results of the Optimal Atherectomy Restenosis Study (OARS), ${ }^{6}$ Balloon $v$ Optimal Atherectomy Trial (BOAT), ${ }^{7}$ and the Adjunctive Balloon Angioplasty following Coronary Atherectomy Study (ABACAS) $^{8}$ (table 3 ). The natural question is: do we still need DCA? If the answer is yes, to what extent and in what situations?

The answer to the original question is "yes" but only in conjunction with stent application. The data to support this statement are early, premature, and few but still quite promising..$^{10}$

Despite attempts to limit the value of the concept "the bigger the better" ing clinical study has been able to disprove this assumption. It has been reported that the combination of DCA and stenting gives the largest post-procedural minimal lumen diameter for a specific reference vessel size. ${ }^{9}$ In addition, if we assume that one of the major mechanisms of restenosis following DCA is vessel contraction, ${ }^{12}$ the application of a stent will effectively counteract this element. The initial results of a registry from two institutions $^{9}$ support the hypothesis that stent implantation following DCA produces a larger lumen compared with either technique alone, and that at follow up the minimum lumen diameter is still quite large with a uniquely low dichotomous restenosis rate (table 4). These are the reasons that justify the use of DCA before stent implantation. In addition to this general framework there are a number of specific lesions where simple angioplasty or primary stent implantation give inferior results.

There are some types of otial lesions, ${ }^{13}$ many bifurcational lesions, ${ }^{14}$ and a number of total occlusions ${ }^{15}$ that are associated with a high restenosis rate, and sometimes with a 

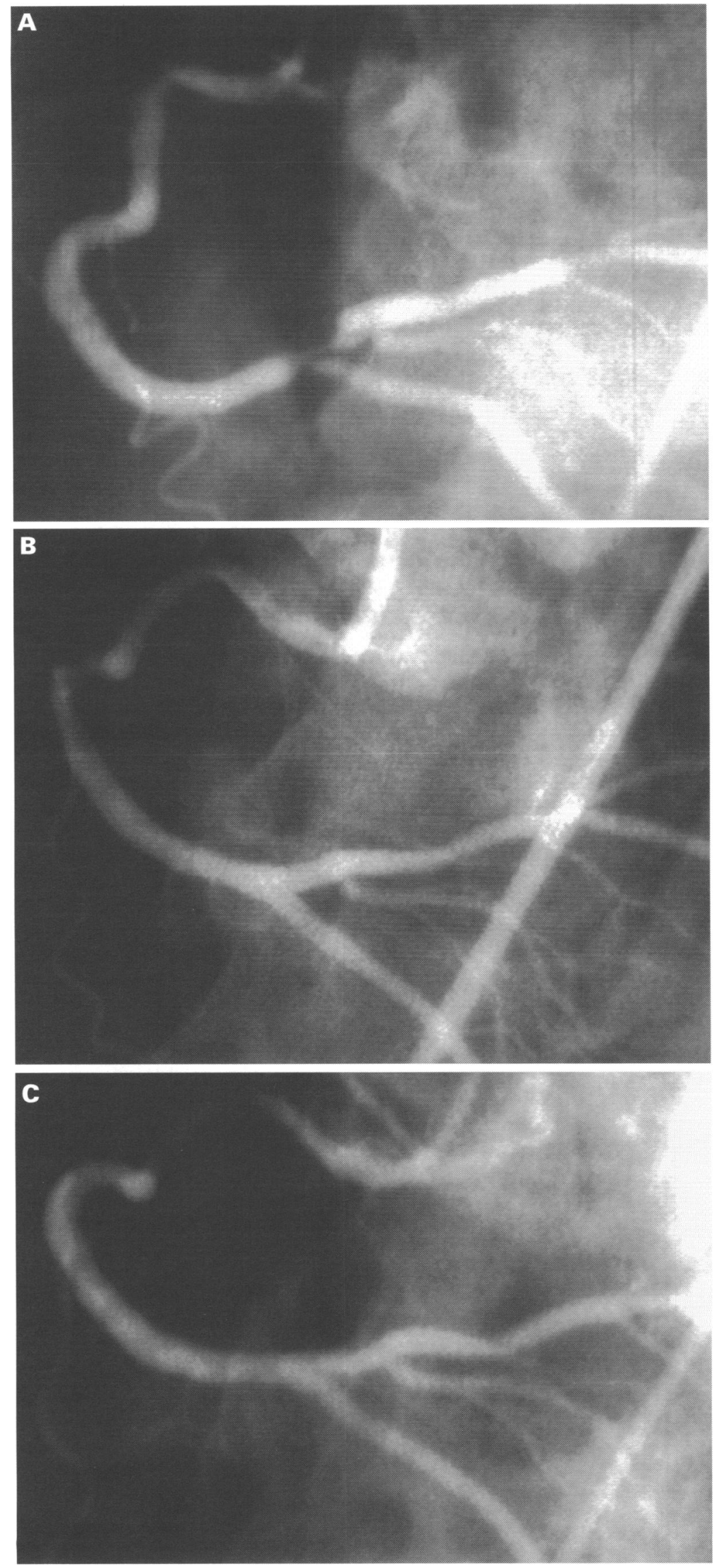

(A) Baseline angiogram of a bifurcational lesion of the distal right coronary artery and of the posterior descending coronary artery. (B) Result following DCA on both branches and implantation of two Multilink stents in a V fashion. (C) Angiographic follow up after five months.

suboptimal immediate result even after stent implantation. In many of these lesions stent implantation without an associated debulking technique such as DCA will produce a significant plaque shift towards the proximal and distal part of the treated lesions, with the consequent risk of branch compromise. ${ }^{16}$ Plaque removal before stent implantation will limit plaque shift and it will allow better stent expansion with the achievement of larger final luminal diameter. The figure shows a typical example where it will be very difficult to obtain a good final result without the application of DCA.

The presence of late vessel contraction following DCA partially negates the immediate achievement and questions the use of DCA alone, especially when we have an effective means (the stent) to eliminate this element of late loss.

There is no doubt that the combination of these two techniques increases procedural complexity and cost, and many may question such a need when the results of contemporary stenting are associated with an angiographic restenosis of $16 \%$ such as reported in the Benestent II trial. ${ }^{17}$

A partial answer is that the spectrum of lesions treated in current clinical practice include a large number of lesions excluded from the Benestent II study and associated with angiographic restenosis almost twice that just mentioned. ${ }^{18}$ Therefore, it appears reasonable to look for alternative modalities even if the proposed approaches are more complex and expensive.

Another objection to the use of DCA that is frequently raised is that this technique can only be applied in large vessels. Without denying this limitation we need to acknowledge that almost $30 \%$ of the lesions treated in the BOAT trial were located in vessels with a reference diameter smaller than $3.0 \mathrm{~mm}$. In addition it is important to consider that the demonstration of the proof of principle of this synergistic approach (DCA and stenting) may stimulate technological refinements to allow DCA in smaller vessels, probably with the use of smaller guiding catheters.

While awaiting the inception of a randomised trial it may be premature to bury the "revived death".

1 Topol EJ, Leya F, Pinkerton CA, Whitlow PL, Hofling B, Simonton CA, et al. A comparison of directional atherectomy with coronary angioplasty in patients with coronary artery disease. $N$ Engl $\mathcal{G}$ Med 1993;329:221-7.

2 Adelman AG, Cohen EA, Kimball BP, Bonan R, Ricci DR Webb JG, et al. A comparison of directional atherectomy with balloon angioplasty for lesions of the left anteior descending artery. N Engl $\mathcal{F}$ Med 1993;329:228-33.

3 Colombo A, Hall P, Nakamura S, Almagor Y, Maiello L Martini G, et al. Intracoronary stenting without anticoagulation accomplished with intravascular guidance. Circulation 1995;91:1676-88.

4 Schömig A, Neumann FJ, Kastrati A, Schülen H, Blasini $\mathrm{R}$, Hadamitzky $\mathrm{M}$, et al. A randomized comparison of antiplatelet and anticoagulation therapy after the placement of coronary-artery stents. $N$ Engl F Med 1996;334: $1084-9$.

5 Karillon GJ, Morice MC, Benveniste E, Bunouf P, Aubry $\mathrm{P}$, Cattan S, et al. Intracoronary stent implantation without ultrasound guidance and with replacement of conventional anticoagulation by antiplatelet therapy. 30-day clinical outcome of the French Multicenter Registry. Circulation 1996;94:1519-27.

6 Simonton CA, Leon MB, Kintz RE, Popma J, Hinohara $\mathrm{T}$, Cutlip $\mathrm{DE}$, et al. Acute and late clinical and angiographic results of directional atherectomy in the optimal atherectomy restenosis study (OARS). Circulation 1995; 93(Suppl):2602.

7 Baim DS, Popma J, Sharma SK, Fortuna R, Schreiber TL, Senerchia C, et al. Final results in the balloon vs 
optimal atherectomy trial (BOAT): 6 months angiography and 1 year clinical follow-up. Circulation 1996, 94(suppl I):I2543.

8 Suzuki T, Kato O, Fujita T, Ueno K, Takase S, Jujii K, et al, for the ABACAS Investigators. Initial and long-term results of the adjunctive balloon angioplasty following coronary atherectomy study (ABACAS) [abstract]. $\mathcal{F} A m$ Coll Cardiol 1997;29(suppl A):68A

9 Moussa I, Moses J, Di Mario C, King T, Reimers B, Colombo A. Immediate and short-term results of the pilot phase of stenting after optimal lesion debulking "The SOLD Trial" [abstract]. $尹$ Am Coll Cardiol 1997; 29(suppl A):415A.

10 Bramucci E, Angoli L, Merlini PA, Barberis P, Kubica J, Laudisa ML, et al. Acute results of adjunct stent following directional coronary atherectomy [abstract]. $7 \mathrm{Am}$ Coll Cardiol 1997;29(suppl A):415A

11 Garratt KN, Holmes DR Jr, Bell MR, Bresnahan JF, Kaufmann UP, Vlietstra RE, et al. Restenosis after direcKaufmann UP, Nietstra RE, et al. Restenosis after direcmary atheromatous and restenosis lesions and influence of subintimal tissue resection. $\mathcal{F} \mathrm{Am}$ Coll Cardiol 1990;16: of subintima

12 de Vrey E, Mintz GS, Kimura T, Nobuyoshi M, Popma JJ, Mehlman $\mathrm{MD}$, et al. Arterial remodeling after directional coronary atherectomy: a volumetric analysis from the serial ultrasound restenosis (SURE) Trial [abstract]. $\mathcal{f} A m$ Coll Cardiol 1997;29(suppl A):280A.

13 Colombo A, Itoh A, Maiello L, Blengino S, Di Mario C,
Zampieri $\mathrm{P}$, et al. Coronary stent implantation in aortoostial lesions: immediate and follow-up results [abstract]. f Am Coll Cardiol 1996;27(suppl A):253A.

14 Colombo A, Maillo L, Itoh A, Hall P, Di Mario C,

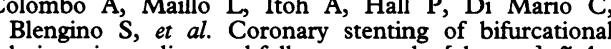
lesions: immediate and follow-up results [abstract]. $\mathcal{F} \mathrm{Am}$ Coll Cardiol 1996;27(suppl A):277A.

15 Sirnes PA, Golf S, Myreng Y, Molstad P, Emanuelsson H, Albertsson $\mathrm{P}$, et al. Stenting in chronic coronary occlusion (SICCO): a randomized, controlled trial of adding stent implantation after successful angioplasty. $\mathcal{F} \mathrm{Am} \mathrm{Col}$ Cardiol 1996;28:1444-51.

16 Honda Y, Yock CA, Hermiller JB, Fitzgerald PJ, Yock PG. Longitudinal redistribution of plaque is an important mechanism for lumen expansion in stenting. $\mathcal{f} \mathrm{Am} \mathrm{Coll}$ Cardiol 1997;29(suppl A):281A.

17 Legrand V, Serruys PW, Emanuelsson H, Fajadet J, Haude M, Klugmann S, et al. Benestent-II trial-final results of visit I: a 15-day follow-up [abstract]. $\mathcal{F} \mathrm{Am}$ Coll Cardiol visit I: a 15-day follow-up

18 Lablanche JM, Danchin N, Grollier G, Bonnet JL, Bedssa $\mathbf{M}$, Vahanian A, et al. Factors predictive of restenosis M, Vahanian A, et al. Factors predictive of restenosis aspirin. $\mathcal{F} \mathrm{Am}$ Coll Cardiol 1996;94(suppl I):1498.

19 Yokoi H, Nobuyoshi M, Nosaka H, Kimura T, Yokoi H, Hamasaki $\mathrm{N}$, et al. Coronary stenting for long lesions (lesion length $>20 \mathrm{~mm}$ ) in native coronary arteries: comparison of three different types of stent. F Am Coll Cardiol 1996;94(suppl I):I685.

\title{
If directional coronary atherectomy is useful then why is it not used more often?
}

\author{
Mazhar Khan
}

Directional coronary atherectomy (DCA) was developed to overcome the limitations of balloon angioplasty. However, three well controlled randomised trials have questioned the use of directional atherectomy. ${ }^{1-3}$ The Coronary Angioplasty Versus Atherectomy Trial (CAVEAT) and the Canadian Coronary Atherectomy Trial (CCAT) were the first published trials comparing the two techniques. The design of the trials was such that post-procedural dilatation was strongly discouraged in the atherectomy arm. Intravascular ultrasound has shown that $60-75 \%$ of the final lumen is created by atheroma removal and the remainder by stretching the external wall of the artery. ${ }^{4}$ In view of the benefit of a large post-procedure lumen in reducing restenosis, the use of balloon angioplasty following successful yet suboptimal ( $>15 \%$ residual stenosis) atherectomy is common practice when additional cuts may be unsafe. ${ }^{56}$ The high residual stenosis in CAVEAT and CCAT $(30 \%$ and $26 \%$, respectively) resulted mainly from avoidance of adjunctive balloon angioplasty. The full potential of atherectomy was therefore not realised. It is not the device itself but its ability to provide a larger lumen that may reduce the risk of restenosis. ${ }^{?}$

\section{Is directional atherectomy useful?}

DCA is useful for lesions unfavourable to angioplasty - for example, ostial, bifurcation, eccentric, and shelf-like lesions. ${ }^{8}$ CAVEAT I and CCAT trials, however, did not confirm that DCA was superior for such lesions. ${ }^{9}$ Although larger luminal gain with reduced residual stenosis was achieved despite the use of first generation devices, the long term outcome was similar. The initial gains were at the expense of complications, mainly non- $Q$ wave infarction.

Newer GTO and short window catheters with flexible nosecones are clearly superior to the first generation devices for bifurcation and ostial lesions. The mechanism of luminal enlargement includes sequential excision of tissue that might otherwise be displaced into the branch ostium during balloon angioplasty, while stent placement may cause adjacent vessel compromise or "stent jail". The new ultrasound guided atherectomy catheter is another advance and will allow safe and aggressive debulking with greater precision. Debulking before stenting is an interesting concept in device synergy. It may lead to safer and easier stent deployment. It may result in a larger acute lumen without the need for high pressure inflation. ${ }^{10}$

\section{Regional Medical The Royal Victoria Hospital, Grosvenor Road, Belfast
BT12 6BA, UK}

